\title{
A produção das vontades de verdade cristã nas inscrições tumulares
}

\author{
Alécia Lucélia Gomes Pereira ${ }^{1}$ \\ Maria Angélica de Oliveira ${ }^{2}$
}

\begin{abstract}
Resumo: O surgimento de um texto, materialidade discursiva, não nasce do acaso, surge da necessidade social de dizer e de ser dito que envolve nosso cotidiano. Através dos textos, divulgamos nossa compreensão acerca do mundo, representamos e retratamos nossa realidade. Através da linguagem, materializada em textos verbais ou não verbais, criamos o real da língua, o real da história. Como exemplos dessas materialidades discursivas, para este trabalho, escolhemos os epitáfios, inscrições tumulares que inscrevem, no mundo dos vivos, as lembranças do sujeito morto. Nosso estudo tem um olhar direcionado à produção dos epitáfios, à organização dos discursos que deles fazem sítio. Para tanto, temos, a luz dos pressupostos teóricos da Análise de Discurso de linha francesa, como objetivo geral identificar e analisar as vontades de verdade cristã na constituição do sujeito morto presentes nas inscrições tumulares. Os textos epitáficos apresentados como corpus desse artigo, resultam de um material fotográfico do cemitério Monte Santo, localizado em Campina Grande - PB. Concluímos que os dizeres dos epitáfios surgem como tentativa de sobrepor à morte de forma contínua, negando a existência de uma ausência definitiva. O sujeito morto ocupa o lugar social de um sujeito moral, retratado sempre como bondoso e "imortal".
\end{abstract}

Palavras-chave: Epitáfio; Memória Discursiva; Relações de Poder.

\begin{abstract}
The emergence of a text, considered here as discursive materiality, is not born by chance, but it comes from the social need to say and to be told which involves our daily life. Through texts, we disclose our understanding of the world; we also represent and portray our reality. Through language, embodied whether in verbal or non-verbal texts, we create the real language, the real story. As examples of such discursive materiality, for this study, we have chosen the epitaphs, tombstone inscriptions which inscribe in the world of the living people, the memories of the dead. The target of our investigation is the production of epitaphs as well as the organization of speeches placed in them. Thus, based on the theoretical assumptions of the French Discourse Analysis, our main aim is to identify and analyze in the tombstone inscriptions the wishes of Christian truths in the constitution of the dead person. The epitaphs that constitute the corpus of this article are the result of a photographic material of a cemetery called Monte Santo, located in Campina Grande - PB ${ }^{3}$. We conclude that the words of the epitaphs seem to be an attempt to continuously override death and so deny the existence of a definitive absence. The dead person assumes a social place of a moral subject, always portrayed as good and "immortal".
\end{abstract}

Keywords: Epitaph; Discourse Memory; Power Relations.

\section{INTRODUÇÃO}

Pensando na dor da perda, na angústia, no medo de não saber para onde se está indo, em síntese, nas diversas dúvidas provocadas em torno do acontecimento morte, alguns procedimentos surgiram como forma de amenização e entendimento da "ausência"

\footnotetext{
${ }^{1}$ Graduada em Letras-Língua Portuguesa pela UFCG e Especialista em Língua Portuguesa pela mesma universidade.

2 Doutora em Letras pela UFPB. Professora de Língua Portuguesa na Unidade Acadêmica de Letras da(3) Universidade Federal de Campina Grande (UFCG). Atua no PPGL- Programa de Pós-Graduação emLetras, da UFPB.

${ }^{3}$ Campina Grande is a city located in the state of Paraíba (PB) in the Northeast of Brazil.
} 
de alguém. Ao visitarmos nossos parentes ausentes fisicamente, no cemitério, visualizamos uma vasta exposição de palavras, frases, mensagens, poesias, textos bíblicos com temas relacionados ao amor, à saudade, à lembrança, à eternidade, à bondade, a Deus. Escritos que são colocados sobre algumas sepulturas como forma de homenagear o morto ou enaltecê-lo perante a sociedade. Tais escritos são os chamados Epitáfios, exemplo de ritual fúnebre, que retrata uma das práticas escritas executadas pós- morte.

Para uns o epitáfio pode ser apenas uma forma de homenagem pública para o morto, a outros revela uma forma de relembrarmos quem foi aquela pessoa, há ainda quem observe nos trechos do epitáfio uma saída para amenizar a dor da morte, outros acreditam que é um ponto de reflexão na ideia de finitude que todos vão passar, há quem o veja como um relato autobiográfico do morto ou há apenas quem o tenha como sendo um texto que delimita temporalmente a estadia de alguém na terra. São essas várias determinações atribuídas a esse gênero que nos leva a estudá-lo, refletindo acerca do lugar que ocupa na sociedade e do lugar reservado ao sujeito morto.

$\mathrm{Na}$ organização desse artigo, em primeiro lugar, apresentaremos breves considerações acerca do gênero epitáfio, em seguida, discutiremos acerca da presença do discurso religioso cristão nos epitáfios selecionados, analisando as vontades de verdade cristã, as relações de poder e o cuidado de si na constituição do sujeito morto. Por último apresentaremos as considerações finais.

Desse modo, temos como como objetivo geral identificar e analisar as vontades de verdade cristã na constituição do sujeito morto presentes nas inscrições tumulares, investigaremos, ao longo do trabalho, como o sujeito morto se subjetiva através do discurso do outro, do discurso cristão.

Os textos epitáficos apresentados como corpus, resultam de uma coleta feita no cemitério Monte Santo, localizado em Campina Grande - PB.

\section{AS INSCRIÇÕES TUMULARES: BREVES CONSIDERAÇÕES}

Conforme Bueno (1965, p.1666), o epitáfio é conceituado como "inscrição tumular. [...]epitáphion, de epi, sobre; táphos, túmulo e suf. io.lat...”. Resumindo, são inscrições sobre os túmulos. Os textos epitáficos antigos (romanos) não eram reduzidos apenas a divulgação de quem foi o ausente, mas cabia-lhe uma função social de instrução comportamental aos presentes, tinham um papel de confissão individual, e, assim como os textos atuais, eram dotados de uma linguagem fácil. Segundo Veyne (1989): “testemunhos 
comprovam que quando um antigo queria ler um pouco, bastava-lhe caminhar até uma das saídas da cidade; era menos difícil ler um epitáfio que a escrita cursiva de um livro" (VEYNE, 1989, p.170) o que era explicável por se tratar de um gênero voltado ao público, à sociedade, tendo por função uma reflexão ou até mesmo uma reivindicação dirigida ao povo.

Cabia aos epitáfios romanos a função de divulgar qual foi o papel do morto, sua posição e seu lugar em vida na sociedade, refletindo sua conduta para os presentes. Ante a isso, a essa preocupação no modo como viveu o morto, a tristeza gerada por sua partida ficava em segundo plano, importante mesmo, ao invés de divulgar a dor causada pela morte, era conseguir a atenção dos que passavam, pois de acordo com Brown (1989) “certos epitáfios procuram atrair a atenção do transeunte entre seus vizinhos; [...]. E todos falam não da dor dos íntimos, mas do papel social do defunto e de sua fidelidade aos deveres para com os seus." (BROWN, 1989, p.170). Acima de tudo estava em questão, nos epitáfios, a propagação da conduta do sujeito morto, o que verdadeiramente importava era apresentar esse sujeito como um sujeito moral, era expor se o morto seguiu as doutrinas de sua sociedade, cumprindo seus deveres de forma moralizante. Nos epitáfios se inscreviam as vontades de verdade da época acerca das boas conduta de dada formação social. Brown afirma que:

$$
\begin{aligned}
& \text { O epitáfio exerce, quando é o caso, um papel de censura; o defunto expõe à } \\
& \text { execração pública aqueles que lhe deram motivos de queixa.Um patrono } \\
& \text { amaldiçoa, como se fazia nos testamentos, um liberto ingrato, trata-o de } \\
& \text { salteador de estrada; um pai informa a todos que deserdou uma filha indigna; } \\
& \text { uma mãe atribui a morte de seu bebê aos malefícios de uma envenenadora.Para } \\
& \text { nós, gravar esse tipo de coisa num túmulo equivaleria a macular a majestade da } \\
& \text { morte.Mas o romanos não lavavam roupa suja em casa; fazia limpeza pública. } \\
& \text { (BROWN,1989, p.170-171). }
\end{aligned}
$$

O papel maior dos antigos epitáfios era, portanto, levar o homem vivo a refletir sobre sua vida, através da vida passada de outro, do morto, reforçando a ideia de que os pensamentos do homem sábio não estão focados no morto, mas naquilo que este foi em vida, é na vida e não na morte que estava focada a preocupação da inscrição epitáfica. Nos atos cometidos por um indivíduo não mais presente que deveria haver um espelhamento. Os mortos ficavam famosos, através do epitáfio, como seres que tinham por função divulgar os preceitos (i)moralizantes conforme a época.Temos aqui uma rarefação do sujeito morto, uma vez que, este entra na ordem do discurso a partir das condições de funcionamento do discurso epitáfico, dessa forma adapta-se a algumas regras exigidas pelo discurso, pois segundo Foucault (2009): 
Ninguém entrará na ordem do discurso se não satisfizer a certas exigências ou se não for, de início, qualificado para fazê-lo. Mais precisamente: nem todas as regiões do discurso são igualmente abertas e penetráveis; algumas são altamente proibidas (diferenciadas e diferenciantes), enquanto outras parecem quase abertas a todos os ventos e postas, sem restrições prévia, à disposição de cada sujeito que fala. (FOUCAULT,2009,p.36)

Apesar do tempo, a prática de escrever para o morto ainda é constante entre nós. Hoje, não temos como função maior a exposição da vida do ausente como reflexão para os que passam. A escrita epitáfica não destina-se mais à regulamentação das condutas, mas a prestar homenagem ao sujeito morto, destacando sempre suas virtudes. De acordo com Gaudêncio (2010),

Um epitáfio narra uma história: marca as datas do nascimento e do fim da existência. No interstício, o que mais merece elogio, o que terá sido a maior virtude do morto, sua maior grandeza [...], além de forma de territorialização/ desterritorialização da morte, é fundamentalmente uma elegia ao morto. (GAUDÊNCIO, 2010, p.)

Hoje, as inscrições tumulares são uma forma de demonstração de carinho própria das relações familiares em nossa formação social. Quando um escrito é destacado em um mausoléu, seja por meio de datas, revelando o período em que o morto esteve entre os vivos, ou através de frases vindas das famílias, de pensamentos filosóficos ou da Bíblia, tem-se a marcação de um lugar dado ao falecido, a construção de seu território, sua moradia, sua história na sociedade. Através da voz e do olhar do vivo, o sujeito morto é inscrito e eternizado na lápide.

\section{INSCRIÇÕES TUMULARES COMO “JOGO DE VERDADE”: UMA (RE)AFIRMAÇÃO DOS DISCURSO RELIGIOSO CRISTÃO}

Ao observamos o gênero epitáfio percebemos que os sujeitos envolvidos em seu discurso entram em um jogo de verdade que nos leva a compreender quais vontades de verdades permeiam seus dizeres, bem como nos faz entender a circulação desse gênero em nossa sociedade com suas intenções. Todo o discurso traz uma vontade de verdade, como coloca Foucault (1979), essa vontade de verdade quando questionada permite-nos conhecermos como o discurso foi formado, bem como dos sujeitos que a formularam. "Por 'verdade', Foucault entende um conjunto de procedimentos regulados para a produção, a lei, a repartição, a circulação e o funcionamento dos enunciados" (FOUCAULT, 1979a, p.14).

Foucault (2009), a partir de Nietzsche, fala em vontade de verdade e não em verdade por se tratar de uma verdade almejada, a qual pode ser questionada, não é uma 
verdade absoluta. A vontade de verdade é um mecanismo de controle de discurso estabelecido através de práticas institucionais, bem como é conduzida "pelo modo como saber é aplicado em uma sociedade, como é valorizado, distribuído, repartido e de certo modo atribuído." (FOUCAULT, 2009, p.17). Entendemos que o epitáfio coloca vontades de verdades em seus dizeres devido ao saber e a valorização que a religião assume em nossa sociedade, que impõe a palavra de Deus como um discurso verídico. A verdade da inscrição tumular associa-se a valores voltados para o cristianismo. De acordo com Orlandi (1987):

A urgência em refletir sobre o cristianismo pode ser vista, por exemplo, no fato de que mesmo nas formas mais agudas de crítica aos poderes instituídos, e nas ditas formas de resistência, se reencontram os valores e o discurso cristão: o ascetismo, a superação, a ênfase no sofrimento, os sacrifício, a humanidade, a salvação etc.” (ORLANDI, 1987, p.09)

Podemos considerar o epitáfio como sendo um "jogo de verdade" por entrar em questão, no seu dizer, o como suas verdades são ditas e quem a diz, a partir de uma relação de poder. O sentido da palavra "jogo" de acordo com Foucault (2004c) relaciona-se a regras que remetem a produção da verdade. Foucault afirma que o jogo de verdade "é um conjunto de procedimentos que conduzem a um certo resultado, que pode ser considerado, em função dos seus princípios e das suas regras de procedimentos." (FOUCAULT, 2004c, p.282). Os jogos de verdade circulam na sociedade por meio das relações de poder, sendo estas encarregadas de conduzir os comportamentos dos outros.

Já perguntava Foucault (1979b, p.179) "Em uma sociedade como a nossa, que tipo de poder é capaz de produzir discursos de verdade dotados de efeitos tão poderosos?" Como resposta, baseando-se no gênero em estudo, temos o poder religioso, o poder do discurso religioso que permite ao epitáfio acentuar vontades de verdade cristãs. E, por meio dessa pergunta podemos fazer uma outra: Quais as vontades de verdades produzidas pelo discurso religioso, discurso de poder, no gênero epitáfio? Essa resposta será dada a partir das análises feitas ao longo desse artigo.

As inscrições tumulares, como jogos de verdade, trazem a imagem que os familiares construíram do sujeito morto em vida, como este era enxergado pelos outros, trazem as vontades de verdade de seu tempo. O epitáfio é o olhar do outro sobre este que agora jaz. As inscrições tumulares destacam desde os hábitos cotidianos às profissões que foram exercidas pelos mortos. 
Os epitáfios são, pois, documentos que tornam permissível a marcação de um espaço físico e o ressurgimento da lembrança de alguém ou rememoração de sua posição na sociedade. Assim como antigamente, a mensagem continua a ser pública, aberta a todos que circulam.

Na maioria dos epitáfios que fazem parte do corpus, pelo olhar e pela voz do vivo, o sujeito morto "retrata", muitas vezes por meio de trechos bíblicos, seu lugar na sociedade como sujeito cristão, sujeito de fé e demente a Deus, para o qual esse sujeito retorna após a morte. Vejamos:

\section{Epitáfio 1}

Combati o bom combate, acabei a carreira,

Guardei a fé. Desde agora, a corda da justiça me está guardada,a qual o Senhor, justo juiz, me dará naquele dia; não somente a mim, mas também a todos quantos amarem a sua vinda.

II Tm.4,7,8

Os versos bíblicos utilizados no epitáfio acima ratificam a importância das vontades de verdade dos valores cristãos, que por meio da fé cristã, são determinantes para que a justiça seja feita. Assim, no epitáfio ratifica-se esse lugar de sujeito cristão, o qual espera a decisão do "justo juiz". O epitáfio, através de seus enunciados, permite que sejam colocadas as vontades discursivas ${ }^{4}$ acerca do lugar que estava o sujeito morto e que está o sujeito vivo na sociedade, enquanto seguidores da doutrina cristã, bem como em torno do lugar reservado a todos: a morte.

A linguagem trazida nos jazigos desde sempre permitiu que homem externasse seus pensamentos ante a morte, as dúvidas que permeiam essa realidade, sua aceitação ou sua recusa. Revela uma imagem de alguém tal como foi em vida ou constrói-se um novo perfil do ente querido.

\footnotetext{
${ }^{4}$ Para Bakhtin (2003) as vontades discursivas dizem respeito às intenções discursivas do falante, as quais permitem inferir uma conclusibilidade do seu enunciado. Sendo essa vontade determinada antes de tudo por meio da escolha de um 
Através do epitáfio podemos visualizar que há uma resistência ao esquecimento, reafirmando as ideias de Focault ditas por Coracini (2010, p.27) de que “... é possível vislumbrar a escrita como um ato de resistência, embora inconsciente: resistência ao anonimato [...], ao silenciamento, ao esquecimento, à sombra a que muitos estão fadados, destinados". Logo, a escrita do epitáfio pode revelar uma resistência até mesmo ante a morte.

Por meio do epitáfio percebemos que há uma preocupação com um passado, quando em muitos é exposto quem foi o morto; com o presente, na medida em que nos faz rememorar e tornar presente algo que falta; assim como com um futuro, quando nos faz refletir acerca desta posição que nos espera, desse fim carnal que todos vamos passar. Essa escrita, de acordo com Gagnebin coloca o “... quão inseparáveis são memória, escrita e morte." (GAGNEBIN, 2006, p.45)

O gênero epitáfio permite que o homem demonstre discursivamente seu posicionamento em relação a essa separação inevitável, vida e morte, revelando os efeitos causados neste acontecimento demarcado pela ausência definitiva de alguém, desvelando a visão consoladora, afetiva e cristã através do(s) discurso(s) que lhe são inerentes.

As inscrições tumulares, bem como todo texto, estão filiadas às condição de produção, ou seja, das situações e dos sujeitos envolvidos, e de uma memória que remota algo já dito, saberes já cristalizados. É devido a essa memória que reafirmamos ou negamos discursos ditos em outros lugares, em outras situações. Essa memória ao ser pensada em relação ao discurso, fixa-se como o interdiscurso, conforme Orlandi (2005).

O interdiscurso consiste na produção de um discurso tendo por base a afirmação ou negação de um já-dito que se encontra na memória discursiva do sujeito falante, mesmo que esse dizer tenha sido dito em outro lugar diferente, em outro momento distante. Assim Orlandi (2007) define o interdiscurso,

como aquilo que fala antes, em outro lugar, independentemente. Ou seja, é o que chamamos memória discursiva: o saber discursivo que torna possível todo dizer e que retorna sob a forma do pré-construído, o já-dito que está na base do dizível, sustentando cada tomada de palavra. (ORLANDI, 2007b, p.31)

Além do efeito de pré-construído temos no discurso um outro efeito, o da articulação, da formulação do dizer, conhecido por intradiscurso. Enquanto o primeiro, interdiscurso, é relacionado a um dizer proferido antes, o segundo, o intradiscurso, relaciona-se a um dizer presente, a organização do dizer, é efeito, manifestação do 
interdiscurso, sendo assim, inter e intradiscurso não são pontos separados, um é efeito do outro.O intradiscurso é efeito do interdiscurso.

Pensando nos dizeres do epitáfio, temos então, que, tudo que foi dito em um outro lugar a respeito de Deus, do céu, da eternidade, da morte, da posição do sujeito após a morte, da boa ${ }^{5}$ conduta que o sujeito deve ter em vida, causa um efeito de sentido no texto desse gênero. Efeito que nos faz colocar o epitáfio tendo por função fazer viver/ressurgir o ser ausente e mais que fazer ressurgir, eternizá-lo, não enquanto matéria corporal, mas como sujeito bom. Nas inscrições tumulares são tecidas as memórias dos discursos de várias épocas. No epitáfio abaixo, vemos esta relação com os dizeres acerca da eternidade e da força produtiva do amor e da bondade. Neste epitáfio, ratifica-se a vontade de verdade de que o sujeito amável e bom terá uma recompensa após a morte, ratifica-se, portanto, a vontade de verdade cristã.

\section{Epitáfio 2}

"O amor que soubestes despertar nos acompanhará por toda vida, como testemunho vivo da tua bondade."

A forma vebal: "acompanhar" marca a eternidade. A forma como tratavam em vida os outros, a conduta que apresentaram em vida sendo espelho para os semelhantes, a crença na salvação da alma, são conceitos que acabam sendo reafirmados nos enunciados do epitáfio. É devido a essa memória do dizer, que o sujeito do epitáfio formula o seu discurso. A memória do dizer traz um já-dito que nos leva a compreender o funcionamento do discurso, bem como a relação que mantém com os sujeitos e a ideologia de um dado grupo social.

Desse modo, a existência de um já-dito na constituição de um texto torna-se necessária para que o mesmo seja formulado e tenha significado. O discurso do bom sujeito está formado pela confluência desses dois eixos conforme afirma Orlandi (2007b), do interdiscurso e do intradiscurso.

Já que todo texto está imbricado por estes dois eixos, constituição e formulação, o epitáfio não fica à parte, sendo através desse entrelaçamento e da relação deste gênero com

\footnotetext{
${ }^{5}$ Foucault (1995,p.243) diz que o termo "é, ao mesmo tempo, o ato de 'conduzir' os outros (segundo mecanismos de coerção mais ou menos estritos) e a maneira de se comportar num campo mais ou menos aberto de possibilidades".
} 
a exterioridade acarretada por uma memória, a qual permite significar nossos ensejos, que o morto é colocado no céu, a desejo da família.

A existência do interdiscurso e do intradiscurso torna-se imprescindível na produção dos enunciados, uma vez que, é devido a essa retomada de palavras outras, de textos ou enunciados já proferidos que o discurso possui um efeito de sentido, um efeito de verdade, que conseguimos averiguar a presença de outros discursos no gênero epitáfio. Vejamos o exemplo:

\section{Epitáfio 3}

$$
\begin{aligned}
& \text { Sorrindo partiste, } \\
& \text { Sorrindo nos deixaste. } \\
& \text { Choramos ficamos, } \\
& \text { Mas sorrindo, hoje, estás } \\
& \text { A contemplar } \\
& \text { A beleza do PARAÍSO. } \\
& \\
& \text { Partiste de nós. } \\
& \text { Hoje, temos de ti } \\
& \text { Uma saudade imorredoura } \\
& \text { Mas dos CÉUS, estás } \\
& \text { A nos contemplar } \\
& \text { Continuando a bela forma de amar } \\
& \text { A lembrança do teu sorriso } \\
& \text { É a força maior do nosso AMOR. }
\end{aligned}
$$

Sabemos, graças a uma memória discursiva que, desde antigamente buscava-se no último momento entregar a alma a Deus. Este colocado como divindade, segundo Ferreira (2001, p. 233) “ser infinito, perfeito, criador do Universo". Redimir-se dos pecados sempre foi uma vontade de verdade adotada por várias formações sociais. Os sujeitos a fim de obter um lugar pós-morte tranquilo ao lado deste ser todo poderoso, arrependem-se de seus pecados.

Neste sentido, o epitáfio em questão reafirma esse posicionamento, o desejo de querer está com Deus após a morte, fazendo uso de palavras já conhecidas por nós, dotadas de valores sentimentais, tais como "saudade" e "amor". Nesta certeza de que o outro está no céu, "região para onde vão as almas dos justos" (FERREIRA, 2001, p.233), conforme nós cristãos aprendemos e cremos; na posição que a família assume em querer que este outro esteja no Paraíso, lugar colocado como bom, que o discurso se estabelece.

A memória discursiva estabelece a materialidade do discurso do epitáfio, permitindo a reafirmação da posição de um lugar bom ao morto e a negação de um outro lugar ao dizer que "estás a contemplar a beleza do PARAÍSO", nega que o sujeito morto 
esteja em um outro lugar oposto ao Paraíso, o inferno, por exemplo, que se representa em nossa formação social como um lugar ruim. Fugindo a conduta moral acredita-se que o sujeito é dirigido para esse lugar, sendo assim fica entendido que fazemos o bem não porque "somos bons", mas sim para não irmos para o inferno. O lugar bom é enfatizado ainda mais devido o destaque em caixa alta das palavras "PARAÍSO" e "CÉUS", aqui postas como sinônimos.

É devido a essa memória do dizer que o discurso do epitáfio é construído e sustentado, memória essa que nos permite retomar algo, e, assim formular os discursos que ali se instauram, pois como afirma Orlandi (2007a, p. 38) "aí se explicita o processo de constituição do discurso: a memória, o domínio do saber, os outros dizeres já ditos ou possíveis que garantem a formulação (presentificação) do dizer, sua sustentação.” Essa memória permite a seleção do discurso do epitáfio, seu controle, destacando o que pode e não pode ser dito.

Vemos também nos epitáfios uma tentativa pela mudança de uma realidade imutável, a finitude gerada pela morte. Através das inscrições tumulares vemos a construção de uma vontade de verdade de que o sujeito morto não tem um fim, mas uma nova vida, uma vida eterna resultante da opção de Deus, com nos diz o seguinte epitáfio:

\section{Epitáfio 4}

Deus optou para mim os melhores dos descobrimentos, o descobrimento da vida eterna, aqui sim eu sou mais feliz, pois tenho o gozo dos anjos e paz perpétua da vida ao som de trombetas e ao cantar dos pássaros aqui eu viverei a eterna festa da paz e desejo a todos para quando morrerem, nos encontrarmos na graça divina.

Vemos aqui a demarcação da presença do discurso religioso, e de uma vontade de verdade que além de remeter a não finitude do sujeito morto, reserva para esse um lugar feliz, junto a Deus, reserva a espera dos entes queridos, que também são eternos.

Além da vontade de verdade voltada a não finitude do sepultado, temos uma outra vontade de verdade no epitáfio, a de querer que o sujeito em posição inerte, no estágio final da vida humana, assuma-se como bom. Em nossa formação social sabemos que um sujeito bom é aquele que segue as leis cristãs. O sujeito é representado sempre e sem exceção por palavras valorativas, referendado como herói, detentor de atitudes admiráveis. Neste momento, temos um contraponto com epitáfio romano que relatava o morto tal como foi, sendo bom ou ruim, pois caracterizava-se por censurar/exaltar a pessoa que morreu e assim 
influenciar os comportamentos dos passantes, primava pelo seguimento dos costumes da época,os costumes tidos por bons e morais, o que revela a vontade de verdade presente nos epitáfios antigos, os vivos deveriam ter por exemplo de vida os bons comportamentos de um morto, viverem com base na conduta do sujeito morto, e, quando este último for colocado como ruim, procurarem não ter as mesmas atitudes.Há uma mudança das mentalidades, uma transitoriedade das próprias vontades de verdade.

Essa vontade de verdade nos faz entender o porquê do epitáfio ser conceituado em alguns dicionários como elogios fúnebres. Não encontramos, em hipótese alguma, epitáfios divulgando mensagens com tom pejorativo. Por mais que o sujeito defunto não tenha sido exemplo em vida, agido contrariamente as boas condutas impostas na sociedade, mesmo assim, após a morte se subjetiva enquanto sujeito bom, exemplar. São essas vontades de verdade que permitem ao discurso do epitáfio significar.

No epitáfio, as relações de poder são estabelecidas pela submissão dos sujeitos cristãos $^{6}$, sujeitos que são livres e podem optar por serem cristãos ou não, a uma autoridade maior, a Deus, representado por meio do discurso religioso ${ }^{7}$. O discurso presente no epitáfio obedece às restrições do discurso religioso.

O morto é colocado na posição de sujeito que em vida respeitou os princípios éticos cristãos, comprovando uma vontade pela verdade de um sujeito sempre bom,

\section{Epitáfio 5}

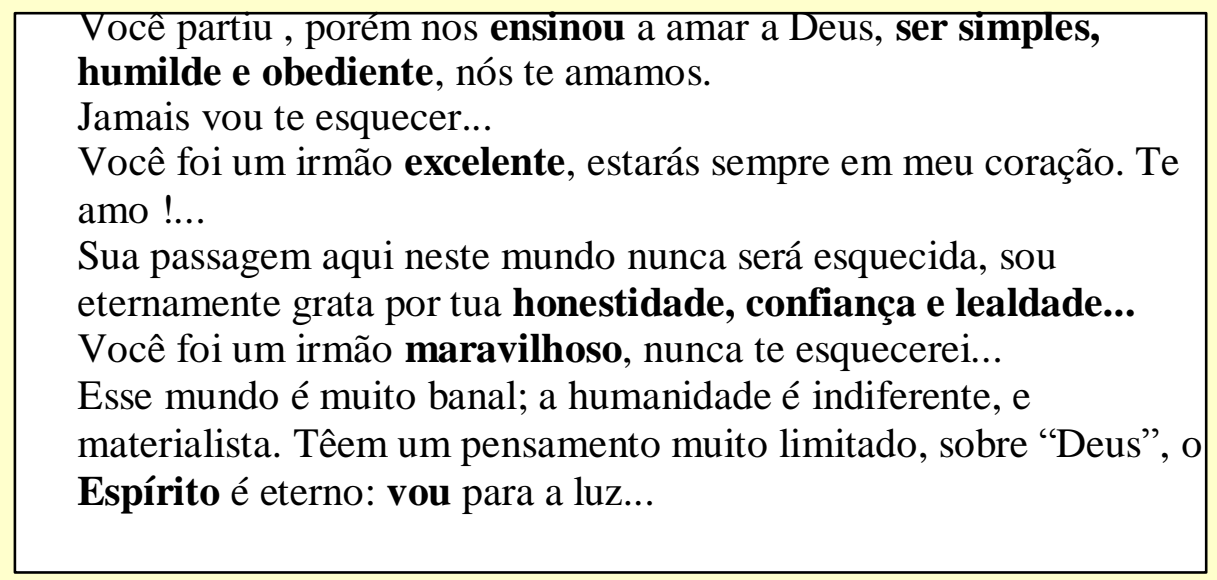

A palavra "ensinou" demarca esse novo lugar do sujeito morto, que agora passa a ser dono de conhecimentos ligados a uma vivência divina em consonância a simplicidade, a humildade, a obediência, a honestidade, a confiança, e a lealdade, virtudes destacadas no

\footnotetext{
${ }^{6}$ O sujeito na ordem do discurso religioso é marcado como submisso de acordo com Orlandi (1987)

${ }^{7}$ Sempre que for mencionado discurso religioso aqui, remetê-lo ao cristianismo.
} 
ausente. Sabemos que o sujeito morto fez parte da humanidade, logo também seria materialista, no entanto, o epitáfio não coloca esse dizer, apenas fala da humanidade como materialista e indiferente, como se o sujeito morto não tivesse feito parte da humanidade. $\mathrm{O}$ morto é dirigido a um lugar espiritual.

Sempre há um enaltecimento do sujeito após a morte, que é colocado na posição de sujeito exemplar, bom. Nos dias atuais, não vemos nas palavras do epitáfio dizeres que remetam a ideia de um sujeito como decepção da família, que não tenha causado orgulho, e não tenha se destacado na sociedade por sua coragem, sua batalha, seu sacrifício.

Dessa forma, temos no epitáfio um poder do discurso religioso impondo a busca pela Salvação do sujeito, para isso inscrevendo-o como exemplar, pois todos os sujeitos, nesse lugar, são adjetivados como seres bons. Ao mesmo tempo prevalece no epitáfio um cuidado de si, na medida em que é seguido as prescrições religiosas cristãs no ato da produção epitáfica "no cristianismo buscar a salvação é também uma maneira de cuidar de si” (FOUCAULT,2004c,p.268). Cuidar de si é ter conhecimento dos princípios de conduta que prescrevem a sociedade como sendo verdadeiros e lançar mão dessa conduta. De acordo com Foucault (2004):

Certamente. Não é possível cuidar de si sem se conhecer. O cuidado de si é certamente o conhecimento de si - [...] -, mas é também o conhecimento de um certo número de regras de conduta ou de princípios que são simultaneamente verdades e prescrições.Cuidar de si é se munir dessas verdades: nesse caso a ética se liga ao jogo da verdade. (FOUCAULT, 2004c, p.269)

\section{CONSIDERAÇÕES FINAIS}

No ato de escrever e inscrever o sujeito morto, de subjetivá-lo, há também uma preocupação consigo mesmo por parte do epitafista, é uma forma de cuidar de si, de nossa conduta individual refletindo o medo da morte.

O epitáfio reflete vontades de verdade em relação a salvação após a morte e ao cuidado de si. Dessa forma, vemos que os dizeres do epitáfio seguem as relações de poder mantidas no quadro cultural de nossa sociedade cristã ocidental.

A escrita coloca-se no lugar de reflexão das condições sociais e culturais, logo é detentora de poder. A escrita epitáfica destaca-se como uma forma de controle do comportamento do sujeito, bem como do próprio autor, do epitafista em relação a uma 
infinitude. O epitáfio através de suas nuances verbais, utilizando-se da escrita permite que a ideia de morte seja amenizada, através de vontades de verdade que tentam colocar o sujeito morto numa posição infinita.

As inscrições tumulares aqui analisadas ratificam as vontades de verdades de uma sociedade majoritariamente cristã. A partir da memória dos dizeres, promulga-se a divulgação de uma concepção de vida eterna e da caracterização do sujeito morto, como sujeito moral, ou seja, sujeito que é conduzido moralmente, agindo em consonância aos preceitos cristãos que são colocados como verdades na formação discursiva do cristianismo.

\section{REFERÊNCIAS}

BAKHTIN, Mikhail. Os gêneros do discurso. In: Estética da criação verbal. Tradução Paulo Bezerra. 4. ed. São Paulo: Martins Fontes, 2003. p. 261-335.

BROWN, Peter. Antiguidade Tardia. In: ARIÉS, Philippe; DUBY, Georges. História da vida privada: do império romano ao ano mil. (Trad Hildegard Feist). São Paulo: Companhia da Letras, 1989, p. 225-300.

BUENO, Silveira. Grande Dicionário Etimológico Prosódico da Língua Portuguesa. São Paulo: Saraiva 1965, p.1.166

CORACINI, Maria José Rodrigues Faria. Discurso e Escrit(u)Ra: entre a necessidade e a (im)possibilidade de ensinar: In: CORACINI, Maria José Rodrigues Faria; ECKERTFERREIRA, Aurélio Buarque de Holanda. Miniaurélio Século XXI: o minidicionário da língua portuguesa. 4.ed.Rio de Janeiro:Nova Fronteira, 2001.

FOUCAULT, Michel. Verdade e Poder. In: Microfísica do Poder. Rio de Janeiro: Graal, 1979a, p.1-14.

.Soberania e Disciplina. In: Microfísica do Poder. Rio de Janeiro: Graal, 1979b, p. $179-191$.

A Ordem do Discurso: aula inaugural no Collège de France, pronunciada em 2 de setembro de 1970.São Paulo:Loyola,2009.

.O Uso dos Prazeres e as Técnicas de Si. In: MOTTA, Manoel Barros da (Org.). MONTEIRO, Elisa; BARBOSA, Inês Autran Dourado (Trad.). Ética, Sexualidade, Política Rio de Janeiro: Forense Universitária, 2004a, p.192-217. 
O Retorno da Moral. In: MOTTA, Manoel Barros da (Org.). MONTEIRO, Elisa; BARBOSA, Inês Autran Dourado (Trad.). Ética, Sexualidade, Política. Rio de Janeiro: Forense Universitária, 2004 b, p.252-263

A Ética do Cuidado de Si como Prática da Liberdade. In: MOTTA, Manoel Barros da (Org.). MONTEIRO, Elisa; BARBOSA, Inês Autran Dourado (Trad.). Ética, Sexualidade, Política. Rio de Janeiro: Forense Universitária, 2004 c, p.264-300.

O sujeito e o poder. In:DREYFUS, Herbert; RABINOW, Paul. Michel Foucault: Uma trajetória filosófica (para além do estruturalismo e da hermenêutica). Rio de Janeiro: Forense, 1995, p. 231-249.

GAUDÊNCIO, Edmundo de. Do Epitáfio: Resto, Rastro, Rosto. In: II Simpósio Nacional de Psicologia e crítica da cultura: Identidades, sujeitos e representações na cultura contemporânea. Campina Grande: Realize 2010. CD-ROM.

GAGNEBIN, Jeanne Marie. Verdade e memória do passado. In: Lembrar escrever esquecer. São Paulo: 34, 2006, p.39-47.

ORLANDI, Eni P. Interpretação: autoria, leitura e efeitos do trabalho simbólico. 5. ed.Campinas, SP: Pontes, 2007a.

. Análise de Discurso: princípios \& procedimentos. 7. ed. Campinas: Pontes, $2007 b$.

Palavra Fé Poder. Campinas: Pontes, 1987.

RICOEUR, Paul. História e Tempo. In: A memória, a história, o esquecimento. (Trad. Alain François). Campinas, SP: Unicamp, 2007, p.357-412.

VEYNE, Paul. O império romano. In: ARIÉS, Philippe; DUBY, Georges. História da vida privada: do império romano ao ano mil. (Trad Hildegard Feist). São Paulo: Companhia da Letras, 1989, pg. 19-224.

Recebido em 15 de julho de 2014

Aceito em 25 de agosto de 2014 